\title{
Processos Verbais No DisCURSO JORNALÍ́STICO: FREQUÊNCIA E ORGANIZAÇÃO DA MENSAGEM
}

\author{
(Verbal processes in media discourse: frequency \\ and organization of the message)
}

\author{
Sara Regina Scotta CABral (UFSM - RS) \\ Leila BARBARA (PUCSP/CNPq)
}

\begin{abstract}
Resumo: Investigar o uso de processos verbais em determinados discursos tem sido o objetivo do Projeto SAL (Systemics Across Languages). Este trabalho tem por objetivo analisar o emprego de cinco verbos que se fazem presentes no discurso jornalístico em língua portuguesa: dizer, afirmar, informar, pedir e anunciar. Empregados em orações verbais, especialmente naquelas em que há o depoimento de fontes externas, esses verbos exercem a função de introduzir o discurso de outrem, como uma forma de conferir autoridade ao dizer do jornalista. A análise está centrada em três aspectos: o tipo de dizente, o modo das orações e a organização da mensagem. Através do uso da ferramenta computacional Word Smith Tools (SCOTT, 2008), os dados foram quantificados a partir de um conjunto de 656 notícias coletadas da Folha de São Paulo e da BBC de Londres no ano de 2009. Os resultados apontam para a existência de três padrões principais utilizados pelos jornalistas ao empregar os cinco verbos analisados. Outras particularidades são: a) dizentes que representam principalmente fontes oficiais, realizados por nomes, pronomes ou grupos nominais em que o modificador indica 0 cargo ocupado; b) predomínio do modo indicativo e do tempo pretérito perfeito, especialmente na terceira pessoa do singular; c) equilíbrio entre citação e projeção, aquela geralmente antecipada ao processo verbal.
\end{abstract}

Palavras-chave: Projeto SAL, discurso jornalístico, processos verbais, projeção, dizente.

Abstract: The main aim of the SAL (Systemics Across Languages) Project is to Investigate the use of verbal processes in some different types of discourse. This paper analyzes the use of five verbs, in Brazilian newspapers: dizer, afirmar, informar, pedir e anunciar (say, affirm, inform, ask and announce, inform, ask and announce). Used in verbal clauses, especially in those with statements from external sources, these verbs have the role of introducing the discourse of another as a way to confer authority to the journalists' statements. The analysis focus on three aspects: the type of Sayer, the mood of the clauses and the organization of the message. By using the computer program WordSmith Tools (SCOTT, 2008), the data were quantified from a set of 656 news collected from Folba de São Paulo and London BBC in 
2009. The results point to the existence of three main patterns used by journalists concerning the five verbs analyzed. Other particularities are: a) Sayers that usually represent official sources, what is done by nouns, pronouns or noun groups in which the modifier indicates the position held; b) predominance of the indicative mood and the simple past tense, especially in the third person singular; c) a balance between quoting and projection, that one generally before the verbal process.

Key-words: SAL Project, journalistic discourse, verbal processes, projection, Sayer.

\section{INTRODUÇÃO}

Em discursos jornalísticos e em uma infinidade de gêneros, primários

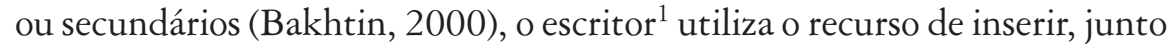
com a sua própria voz, a voz do outro, normalmente alguém legitimado na área em questão. Léxico-gramaticalmente, a referência às fontes é realizada através de vários recursos nas notícias veiculadas pela mídia, seja em jornais impressos ou em versões digitais.

As vozes apontadas como recurso de autoridade são tecidas no texto jornalístico e constituem prática comum em notícias, sejam elas impressas ou online. Quando uma voz é utilizada para moldar outra, os traços que circundam o discurso citado ou reportado devem ser objeto de investigação. O discurso autoral e o discurso das fontes externas são unidades que entram na composição da notícia através do uso de diferentes tipos de elocução, o que pode ser analisado através da.abordagem sistêmico-funcional da oração e dos complexos oracionais.

O presente trabalho tem por objetivo analisar o contexto linguístico em que ocorrem cinco processos verbais em notícias de dois jornais publicados em português, a partir de sua manifestação na internet, coletadas no período de 16/04/2009 a 02/06/2009, e organizadas de modo a serem examinadas usando-se a ferramenta computacional Word Smith (Scott, 2008).

Esta pesquisa prioriza a metafunção ideacional, mas também faz algumas incursões na interpessoal e na textual. Realiza-se como uma contribuição ao Projeto SAL (Systemics Across Languages), instituído por uma equipe plurinacional de pesquisadores liderados por Christian Mathiessen,

1. Usa-se aqui os termos "autor", "escritor" e "jornalista" como sinônimos. 
Kazushiro Teruya e Leila Barbara, que busca a descrição da gramática de diferentes línguas dentro da teoria sistêmico-funcional a partir de gêneros.

No decorrer deste artigo, apresenta-se a caracterização dos dizentes dos processos verbais selecionados. Logo após, apontam-se os achados referentes às formas verbais e ao modo das orações e, por fim, faz-se o exame da constituição das mensagens em termos de projeção de orações e presença de citações e de relatos. Tais procedimentos constituem uma tentativa de se reconhecerem padrões de organização do discurso do jornalístico quando ele constrói orações verbais.

\section{A ORAÇÃo VERBAL}

Inumeráveis discursos servem-se de orações verbais para promover trocas simbólicas de sentidos e apresentar posicionamentos dialógicos. No discurso jornalístico, tendo em vista a preocupação com o depoimento das fontes, os processos verbais são muito utilizados, o que ocorre frequentemente em notícias.

Segundo a gramática sistêmico-funcional (Halliday \& Matthiessen, 2004), a oração verbal está constituída de um participante principal - o dizente - e de um processo que indique atividade de fala, além de outros participantes opcionais - a Verbiagem (o que é dito), o Recebedor (a quem é dirigida a mensagem) e o Alvo (a entidade atingida pelo processo de dizer). Muitas vezes circunstâncias também se fazem presentes.

Um participante de uma oração é representado lexicogramaticalmente por atributos e coisas (ordinárias, na expressão de Halliday e Matthiessen, 1999, p. 60) que obedecem a um sistema semântico que faz a diferença entre consciente e não consciente. As coisas conscientes, segundo os autores, são representadas prototipicamente por humanos, e as não conscientes, por materiais e semioses. Encaixam-se nas coisas materiais os animais (cão, pássaro), os objetos (casa, xícara), as substâncias (terra, álcool) e as abstrações materiais (cor, profundidade). São semioses as instituições (ministério, escola), os objetos semióticos (notícia, história) e as abstrações semióticas (evidência, fato).

Normalmente exercem o papel de dizente (aquele que fala), em uma oração verbal, nomes ou grupos nominais que se referem a seres conscien- 
tes, representados lexicogramaticalmente com nomes comuns (o ministro, o jogador de futebol), nomes próprios (Dilma, Carlos Crusius), ou mesmo com pronomes pessoais (você, elas). Entretanto, algumas formas não congruentes são observadas nessa função, em que objetos ou semioses ocupam o lugar do dizente (a agência, a nota).

Quanto à posição dentro da oração, o dizente pode estar anteposto ao processo ou posposto. Há casos, em língua portuguesa, em que o dizente não se manifesta, especialmente quando é utilizada a voz passiva, como em “Os resultados devem ser anunciados no sábado." (BBC, 13.05.09).

Os processos verbais situam-se em um contínuo entre os relacionais e os mentais, "compartilhando características de ambos e, assim, constituindo um tipo em particular" (Halliday \& Matthiessen, 2004, p. 171). Os processos verbais dividem com os mentais a capacidade de projetar fenômenos de segunda ordem e com os relacionais a capacidade de admitirem como participante um dizente não humano, o que lhe confere característica de processo simbólico.

As orações com processos verbais contribuem, por sua característica de fala, para a existência de passagens dialógicas; permitem ao jornalista atribuir informações a fontes exteriores (oficiais, experts, testemunhas oculares, etc.) e desempenham um relevante papel também nos trabalhos acadêmicos, citando e relatando a fala de pesquisadores.

Os processos de dizer realizam-se através de verbos ou de grupos verbais, segundo duas características principais: os verbos de atividade e os de semiose (Halliday \& Matthiessen, 2004). No primeiro grupo, encontram-se verbos como elogiar, insultar, abusar, caluniar, lisonjear, criticar, culpar, repreender, falar e conversar. Dentre os processos verbais de semiose, os autores citam contar, relatar, anunciar, informar, explicar, provar, prometer, perguntar, interrogar, indagar, dizer, ordenar, mandar, ameaçar, suplicar, implorar, rogar e outros.

O Recebedor representa o participante a quem é dirigida a mensagem, como "lhe" em "O presidente reuniu sua equipe de juristas semana passada, e disse-lhe ..." (FSP, 13.05.09) e "à BBC Brasil” em "Tenho que repetir as fotos 10 , às vezes 15 vezes para ter a imagem perfeita”, contou Skarbakka à $\underline{B B C ~ B r a s i l}$. Léxico-gramaticalmente, o Recebedor é representado, em português, por grupos preposicionais ou por pronomes pessoais oblíquos. 
O Alvo é a entidade atingida pelo processo de dizer e sobre o qual o dizente age verbalmente. Orações verbais que apresentem Alvo dificilmente projetam orações. No exemplo a seguir, apresenta-se um exemplo desse participante: "As declarações do líder cubano foram feitas três dias depois que ele acusou o governo mexicano de não informar sobre a doença na visita do presidente americano, Barack Obama, ao México" (FSP, 14.05.09).

O dizer, elemento complementar dos processos verbais, pode estar representado de duas maneiras diferentes na oração verbal: através do participante Verbiagem ou através de projeção.

A Verbiagem representa o que é falado e pode indicar o conteúdo do que é dito, o nome do dizer ou o nome de uma língua. A Verbiagem é realizada geralmente por um grupo nominal que, em muito casos, constitui uma nominalização do que é dito. Em orações verbais, é comum o papel de Verbiagem ser realizado por outra oração, esta última projetada.

A projeção é a relação lógico-semântica através da qual a oração passa a funcionar não como uma representação direta da experiência (não linguística), mas como uma representação da representação (linguística). São usos discursivos comuns da projeção: atribuir fontes em notícias, representar pontos de vista no discurso científico, construir diálogo na narrativa, enquadrar questões na conversação.

Há três sistemas envolvidos na diferenciação dos tipos de projeção: o nível de projeção (locução vs. ideia), a função de fala (proposição projetada vs. proposta projetada) e o modo de projeção (citação paratática vs. relato hipotático). Através da projeção, uma oração torna-se a representação do conteúdo linguístico de outra - ou o conteúdo de uma oração verbal de dizer(locução) ou o conteúdo de uma oração mental de sentir (ideia). Este trabalho enfoca a análise de locuções no contexto das notícias selecionadas.

A projeção combina a oração projetante com a oração projetada segundo duas relações táticas de interdependência: a parataxe, que é caracterizada pela citação, e a hipotaxe, que é caracterizada pelo relato. Citação e relato não são simplesmente variantes formais; diferem em significado. Na citação, o elemento projetado tem status independente, é mais imediato e real. A citação é usada para ditos e pensamentos, incluindo pensamentos não só de primeira pessoa como de terceira. No relato, o elemento projetado é dependente, não funciona como um movimento na interação. 
A forma mais simples de projeção é o discurso direto, em que a oração projetante é uma oração de processo verbal, de dizer, e a oração projetada representa o que é dito. Há inúmeros usos desse tipo de nexo de citação - material de testemunhas oculares em notícias, passagens dialógicas em narrativas, cenas em biografia, citações no discurso científico.

Num nexo de citação, a relação tática, o tipo de dependência, é a parataxe: as duas partes têm status igual. A oração projetada retém todas as características interativas da oração como troca, vocativos, expletivos, tons e continuativos textuais.

Uma proposição reportada tipicamente assume um conjunto de características coletivamente chamadas de "discurso indireto". Todos os elementos dêiticos são mudados da referência para a situação de fala. O princípio que sustenta a representação hipotática de um evento verbal não é, na realidade, a fidelidade ao enunciado; o falante reporta o ponto principal do que é dito, e o enunciado pode ser bem diferente do original. Isso não significa que, quando um falante usa a forma paratática, direta, ele está sempre repetindo as palavras exatas. Frequentemente as orações verbais são acompanhadas por circunstâncias, geralmente de tempo ou de lugar.

Trabalhos anteriores preocuparam-se com a descrição dos processos verbais em língua portuguesa. Barbara e Macêdo (2010) descrevem padrões de realização da mensagem em discurso acadêmico, ao analisarem artigos de revistas do Scielo Brasil. O trabalho de Cruz (2003) examina os verbos de elocução na obra "Harry Potter and the Chamber os Secrets", nas versões em inglês e português, a fim de determinar padrões de textualização. Fuzer (2008), em trabalho sobre operadores do direito em autos de um processo penal, defende que os processos verbais específicos do sistema de gêneros realizam ações. Motta-Roth e Marcuzzo (2010) apresentam estudo sobre o discurso reportado e Marcuzzo (2011) analisa as vozes não autorais em discursos de popularização da ciência. Sayão (2011), também na perspectiva da linguística sistêmico-funcional, faz uma investigação dos processos verbais quando aborda as falas de entrevistados em exemplares de jornalismo literário.

Em língua inglesa, são proeminentes os trabalhos de Halliday e Matthiessen (1999; 2004) sobre os processos verbais na gramática sistêmicofuncional, de Thompson e YeYiYun (1991) acerca da avaliação utilizada pelos verbos de relato utilizados no discurso acadêmico. Hunston (1995) e Caldas-Coulthard (1994) também têm trabalhos sobre os verbos de atribuição, especialmente no discurso jornalístico. 


\section{Metodologia}

O corpus selecionado está constituído de notícias veiculadas na Folha de São Paulo e na BBC em português nas seções "Notícias" e "Primeira Página", respectivamente, resumidas na Tabela 1, num total de 656 notícias e 314.638 palavras. Os temas abordados nas notícias são variados: política, saúde, futebol, artes plásticas e visuais, desastres, confrontos, moda e culinária.

Tabela 1: Caracterização geral do corpus

\begin{tabular}{|l|c|c|c|}
\hline Jornal & Folha de São Paulo & BBC em português & Total \\
\hline Número de textos & 362 & 294 & 656 \\
\hline Número de palavras & 169.386 & 145.252 & 314.638 \\
\hline Número de bits & 858.141 & 748.098 & 1.606 .239 \\
\hline
\end{tabular}

Inicialmente, através do uso da ferramenta WordSmith Tools (SCOTT, 2008), foi elaborada uma Lista de Palavras, sendo tomado como ponto de corte o quinto verbo mais frequente na sequência. São eles: dizer, afirmar, informar, pedir e anunciar, que foram pesquisados em todos os tempos e formas com que se apresentaram no corpus. $\mathrm{Na}$ etapa seguinte, foram examinadas todas as concordâncias de todos os itens, a fim de excluir usos homônimos ${ }^{2}$ dos processos verbais, o que resultou nos dados da Tabela 2.

Tabela 2: Verbos mais frequentes

\begin{tabular}{|c|l|c|c|}
\hline $\mathbf{N}^{\mathbf{0}}$ & Palavra & Frequência & $\%$ \\
\hline 1 & dizer & 1796 & 1,1 \\
\hline 2 & afirmar & 865 & 0,3 \\
\hline 3 & informar & 287 & 0,1 \\
\hline 4 & pedir & 229 & 0,07 \\
\hline 5 & anunciar & 183 & 0,05 \\
\hline
\end{tabular}

2. Considera-se uso homônimo o emprego de itens lexicais idênticos mas com funções diferentes na oração. Por exemplo; em "Mal informado, o senador tucano apontou o repórter da Folha Online como responsável não só por esse título..." (FSP, 20.05.09), "informado” tem função de Atributo e não, de processo verbal. É, portanto, um uso homônimo do verbo. 
Após, foi feita a análise das orações encontradas, a fim de identificar o dizente das orações verbais e as características da organização da mensagem em termos de utilização de citações, relatos e Verbiagens e da sua localização no complexo oracional.

Por fim, buscou-se estabelecer os padrões de realização da mensagem em orações verbais portadoras dos cinco processos analisados, de modo a perceber regularidades no discurso das notícias.

\section{RESUlTAdOS E DISCUSSÃO}

\section{Os dizentes em notícias de jornal}

As escolhas léxico-gramaticais realizadas pelos jornalistas apresentaram grande diversidade no corpus, embora algumas preferências possam ser identificadas. A tabela 3 constitui um apanhado da natureza dos dizentes no corpus em análise e os dados mais relevantes encontram-se destacados em cor cinza.

Tabela 3: Tipos de dizentes presentes no corpus

\begin{tabular}{|l|c|c|c|c|c|c|}
\hline & dizer & $\begin{array}{c}\text { afir- } \\
\text { mar }\end{array}$ & $\begin{array}{c}\text { infor- } \\
\text { mar }\end{array}$ & pedir & $\begin{array}{c}\text { anun- } \\
\text { ciar }\end{array}$ & TOTAL \\
\hline nomes genéricos e/ou hiperônimos & 89 & 38 & 47 & 49 & 32 & 255 \\
\hline nomes de pessoas & 744 & 386 & 24 & 54 & 21 & 1229 \\
\hline nomes de pessoas e cargo & 281 & 158 & 9 & 26 & 14 & 488 \\
\hline nomes de cargos, funções, ocupações & 281 & 117 & 14 & 19 & 9 & 440 \\
\hline $\begin{array}{l}\text { nomes de instituições, empresas ou partidos } \\
\text { políticos }\end{array}$ & 100 & 69 & 139 & 18 & 76 & 402 \\
\hline nomes de cidades, estados, países & 27 & 12 & 13 & 12 & 19 & 83 \\
\hline pronomes pessoais & 125 & 26 & 2 & 27 & 3 & 183 \\
\hline números e porcentagens & 18 & 5 & 0 & 1 & 0 & 24 \\
\hline objetos semióticos & 103 & 44 & 28 & 4 & 2 & 181 \\
\hline outros & 12 & 2 & 10 & 6 & 5 & 35 \\
\hline TOTAL & 1796 & 865 & 287 & 229 & 183 & 3360 \\
\hline
\end{tabular}

Pode-se observar, pela tabela 3 que metade dos dizentes no corpus são nomes de pessoas, acompanhados ou não de seu cargo, na sua maioria 
aqueles combinados com dizer e afirmar,os verbos responsáveis pela maioria das falas.

Ainda destacam-se os dizentes representados apenas por funções ou ocupações, estes um recurso coesivo nas notícias analisadas, uma vez que a identificação nominal do dizente já havia sido informada anteriormente nos textos. Quanto aos representados por nomes de instituições empresas ou partidos políticos são também frequentes e distribuídos entre os quatro verbos.A referência a pessoas jurídicas, e não físicas, acrescenta legitimidade à informação e ao anúncio, agregando, à responsabilidade daquele que efetivamente diz, a credibilidade da instituição.

Embora em número menor de ocorrências, os objetos semióticos merecem destaque, pois, com dizer e afirmar apresentam um número razoável pedir são com nomes genéricos ou hiperônimos e nomes próprios, geralmente os sobrenomes.

Essa variedade de realização de dizentes no corpus de estudo está nos exemplos 1 a 8 . Podem ser seres conscientes realizados por nomes comuns, geralmente indicadores da profissão da pessoa (1), nomes próprios (2), nomes genéricos e/ou hiperônimos (3), pronomes pessoais (4), pronomes relativos (5) ou sintagmas nominais em que a instituição se faz presente (6).

(1) [No fim da entrevista, realizada em 16 de março, Justus avisou aos jornalistas da presença do Impostor, mas mesmo assim deixou que ele gravasse o quadro.] $\underline{\mathrm{O}}$ publicitário ainda pediu que o humorista mandasse um abraço para Emílio Zurita, apresentador do "Pânico". (FSP, 25.05.09)

(2) José Carlos Araújo disse ontem que não vai mudar a sua posição de trocar o relator, mas não revelou quem seria indicado. (FSP, 13.05.09)

(3) Cientistas anunciam avanço em criação de 'manto de invisibilidade'. (BBC, 01.05.09)

(4) Ele [o deputado Phil Hope] anunciou que vai devolver cerca de 41,7 mil libras esterlinas (a cerca de $\mathrm{R} \$ 130$ mil) que ele havia cobrado dos cofres públicos para mobília e outros itens em sua segunda casa durante cinco anos. (BBC, 13.05.09)

(5) A quantidade de pessoas que pediram seguro-desemprego aumentou em 73,7 mil em março, atingindo a marca de 1,46 milhões. (BBC, 22.04.09)

(6) O presidente da OAB-RS disse que as incertezas sobre o caso "estão sangrando o Estado e a sociedade tem o direito de saber a realidade dos fatos." (FSP, 12.05.09) 
A indicação de cargos, profissões, hiperônimos e pronomes se justifica pela necessidade que o redator tem, ao elaborar seu texto, de utilizar elementos de coesão, a fim de que o texto não se torne tão repetitivo.

Os seres não conscientes que realizam o papel de dizente no corpus analisado são caracteristicamente semióticos: instituições e objetos semióticos. As instituições estão representadas por nomes de partidos políticos (7), nomes de países (8), nomes de empresas (9) e instituições (10), como em 7 a 10.

(7) ...o PSDB diz que "irresponsáveis são as diretorias "severinas" de furar poço", o loteamento de cargos e não fiscalizar a estatal. (FSP, 16.05.09)

(8) A China disse se opor "resolutamente" ao teste nuclear após horas de silêncio. (FSP, 25.05.09)

(9) A Ford Motor anunciou um prejuízo de US\$ 1,4 bilhão no primeiro trimestre, com uma queda de $37 \%$ na receita. (FSP, 24.04.09)

(10) O governo federal afirmou que os Estados brasileiros que apresentaram casos autóctones não devem ser considerados como áreas afetadas. (FSP, 12.05.09)

Os usos desses recursos linguísticos concorrem para conferir mais credibilidade ao jornalista autor da notícia, que se acerca de autoridades nas diferentes áreas para comprovar aquilo que está informando.

Os objetos semióticos estão representados por itens lexicais como "boletim", "comunicado", "nota" e "evento", dentre outros.

(11) Boletim médico divulgado às $11 \mathrm{~h} 40$ de hoje informa que ela [presidente Dilma] está estável e medicada. (FSP, 19.05.09)

(12) Um comunicado do Ministério das Relações Exteriores afirma que tais qualificações são consequência de o relatório não se basear em questões próprias, mas tomar como base exclusiva fatos narrados pela imprensa. (FSP, 09.05.09)

(13) A nota do Itamaraty diz que o assunto (o discurso do presidente Ahmadinejad) será tratado no encontro entre os dois presidentes. $\mathrm{O}$ assunto está na pauta? (BBC, 01.05.09)

(14) $\mathrm{O}$ evento, que acontece entre 2 e 12 de setembro, também anunciou que vai entregar prêmios pela carreira para o diretor criativo e os quatro diretores do estúdios de animação Pixar pelo seu trabalho. (BBC, 11.05.09) 
As categorias citadas acima ocorrem com os cinco verbos pesquisados: dizer, afirmar, informar, pedir e anunciar, em maior ou menor número. Entretanto, destaca-se o verbo "afirmar", em que há a presença intensiva de nomes de pessoas acompanhados de seus cargos e/ou funções, o que lhes dá legitimidade para fazer afirmações importantes. Quanto ao verbo "anunciar", bem menor é o número de nomes de pessoas, prevalecendo a voz das instituições a que elas pertencem.

(15) $\mathrm{O}$ premiê paquistanês, Yusuf RazaGilani, afirmou nesta segunda-feira que a ofensiva do Exército do país contra alvos do grupo radical islâmico Taleban só será encerrada quando os insurgentes “depuserem as armas” e se renderem. (FSP, $11.05 .09)$

(16) Na quinta-feira, a rival Chrysler anunciou que fechará 789 concessionárias nos EUA, como parte de seu programa de reestruturação.. (BBC, 16.05.09)

Não há, no corpus analisado, abstrações semióticas ("noção", "ideia ", "fato", "princípio") que representem os dizentes, como, por exemplo, *O princípio diz que todos estão assegurados, o que parece se relacionar às características do gênero notícia, no qual não cabem citações ou relatos advindos de falantes que não sejam representativos de alguma instituição ou ocupação.

Passando à posição ocupada pelos dizentes nas orações com os processos verbais selecionados, as possibilidades estão resumidas na Tabela 4 .

Tabela 4: Os dizentes nas notícias da FSP e da BBC

\begin{tabular}{|l|c|c|c|c|c|c|c|}
\hline Verbos & $\mathbf{N}^{\circ}$ & anteposição & $\%$ & posposição & $\%$ & $\begin{array}{c}\text { Outras } \\
\text { formas }\end{array}$ & $\%$ \\
\hline dizer & 1796 & 1127 & 34 & 619 & 19 & 50 & 1,5 \\
\hline afirmar & 865 & 668 & 19 & 195 & 5,8 & 2 & 0,05 \\
\hline informar & 287 & 198 & 6 & 79 & 2,3 & 10 & 0,3 \\
\hline pedir & 229 & 223 & 6,7 & 5 & 0,1 & 1 & 0,02 \\
\hline anunciar & 183 & 174 & 5,13 & 5 & 0,1 & 4 & 0,1 \\
\hline \hline TOTAL & 3.360 & 2.390 & 70,83 & 903 & 27,2 & 67 & 1,97 \\
\hline
\end{tabular}

A tabela 4 indica, em número e porcentagem, a predominância dos dizentes antepostos (2.390 correspondendo a $70,83 \%)$, portanto seguindo 
a ordem canônica em português. As posposições do dizente correspondem a mais de um quarto das ocorrências $(27,2 \%)$ do corpus analisado, ficando para outras posições apenas $1,97 \%$. Dos dizentes pospostos, a maioria ocorre com dizer (19\%), seguida de afirmar (5,8\%) e informar (2,3\%), e há pouca ocorrência de pedir e anunciar ( $0,1 \%$ cada). Tanto a tabela 4 quanto a figura 1 , com os mesmos dados, evidenciam a diferença no uso dos cinco processos: dizer com a metade do total de ocorrências, seguido de afirmar, com um quarto, e os três outros processos responsáveis por um quarto do total.

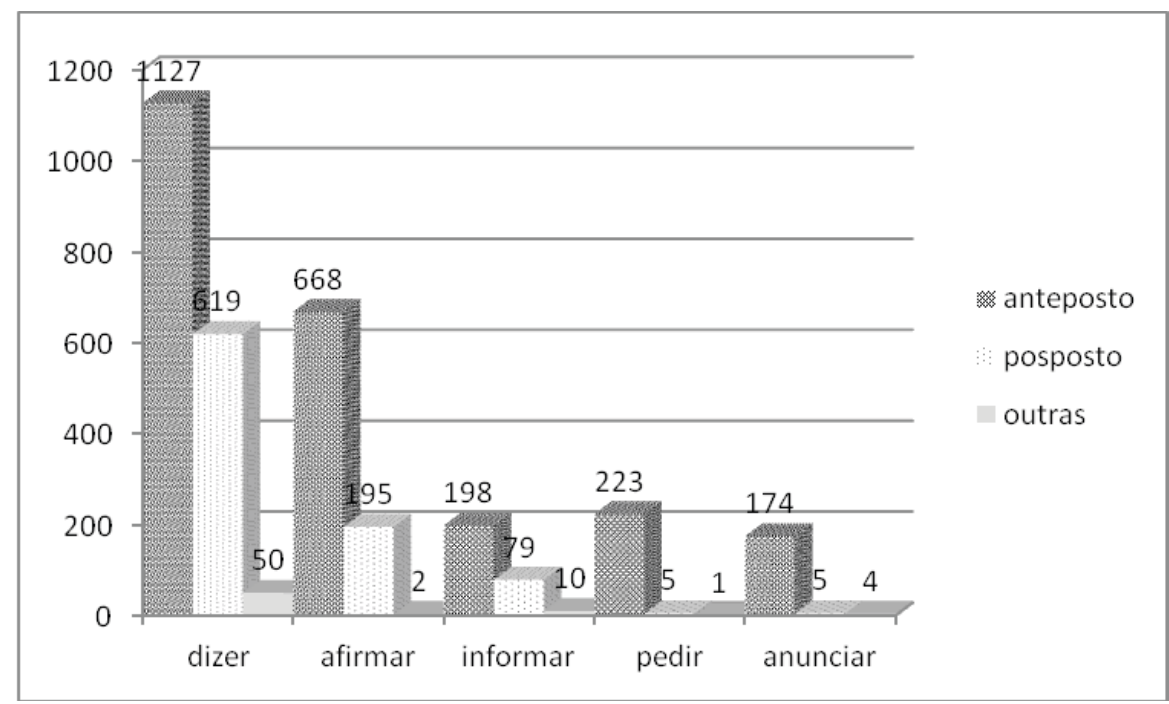

Figura 1: Posição dos dizentes no corpus.

Quando os dizentes estão pospostos, nota-se um grande número de ocorrências em três verbos principais: dizer (17), afirmar (18) e informar (19), com privilégio do primeiro. Com "pedir" (20) e "anunciar" (21) os números são inexpressivos ( 5 ocorrências para cada um).

(17) "Assim não tem condições de a gente estudar", diz Gabriel Nunes, 17. (FSP, 13.05.09)

(18) "Essa também foi a primeira vez que houve uma retração nesse mercado na comparação ano a ano no primeiro trimestre, período em que as vendas são fortes na região da Ásia e do Pacífico", afirma Carolina Milanesi, diretora de pesquisas para o setor de celulares, em nota. (BBC, 16.05.09) 
(19) O governo dos Estados Unidos calculou que o Bank of America precisa captar entre US \$33,9 bilhões e US \$ 35 bilhões extras para superar eventual agravamento da recessão no país, informam os jornais "The New York Times" e "The Wall Street Journal”. (FSP, 06.05.09)

(20) É o que pede a oposição... (BBC, 01.05.09)

(21) A apresentação está marcada para o dia 24 de outubro, segundo anunciou a assessoria do evento nesta quarta-feira ... (FSP, 13.05.09)

Tanto os dizentes pospostos como os antepostos privilegiam nomes de instituições e de objetos semióticos. Essa escolha privilegiada de nomes de instituições em posição posposta anuncia, no corpo da mensagem, a importância do dito, que aparece em primeiro lugar, complementada pela informação com as credenciais da fonte. A anteposição do dito, neste caso, constitui um Tema marcado na terminologia de Halliday e Matthiessen (2004).

(22) O chefe de um cartel de narcotraficantes mexicano que atua no balneário de Cancun foi preso com nove cúmplices, entre os quais sua amante brasileira, anunciou neste sábado a Secretaria da Defesa do México (Sedena). (FSP, 09.05.09)

(23) "Seu objetivo é criminalizar práticas cotidianas na internet, tornar suspeitas as redes $\mathrm{P} 2 \mathrm{P}$ [peer-to-peer, que possibilitam a troca de arquivos on-line], impedir a existência de redes abertas e reforçar o DRM [sistema que limita o número de cópias possíveis de um arquivo], o que impedirá o livre uso de aparelhos digitais", afirma o manifesto que convoca a manifestação, chamada "Ato Contra o AI-5 Digital", marcada para a Assembleia Legislativa de São Paulo, às 19h. (FSP, 11.05.09)

Como se vê pela última coluna da tabela 4 , há um número muito pequeno de dizentes não realizados lexicalmente (24, 25 e 26), por indeterminação ou uso de passiva.

(24) ... o número de pessoas que já morreram no conflito em Darfur é "menos de um décimo do que tem sido dito". (BBC, 12.05.09)

(25) O presidente Luiz Inácio Lula da Silva foi informado sobre o desaparecimento do avião da Air France por volta de 5h50, horário de San Salvador (8h50 de Brasília), e está recebendo relatórios sobre as buscas para encontrar a aeronave de hora em hora. (BBC, 01.06.09)

(26) Em 2007 foi anunciado que Hawking deixaria o cargo em Cambridge, pois a política da universidade é de aposentadoria para os professores que têm este título aos 67 anos. (FSP, 20.04.09) 


\section{FORMAS VERBAIS E COMPLEMENTOS}

Um levantamento preliminar (ver tabela no anexo) aponta alta variação nas orações com os cinco processos de semiose (HaLliday \& MATthiEsSEN, 2004: 255) analisados, principalmente com o processo dizer, o mais frequente, o que permitiu observar 58 formas no conjunto dos 5 verbos.

Outra característica que distingue o grupo de processos estudado é que o mais frequente, dizer, é justamente o verbo de elocução mais neutro. Anunciar, informar e afirmar podem ter dizente diferente do sujeito da oração projetante e afirmar e dizer priorizam ocorrências sem ouvinte. Esses quatro processos são típicos de proposições, em que o dizente oferece informações ao ouvinte (diz, afirma, informa e anuncia proposições).

Quanto ao potencial de interpessoalidade, em orações com os cinco processos mais frequentes, somente um não tem potencial para apresentar proposições. Pedir, dentre as 229 orações em que ocorre no corpus, é sempre complementado com propostas, com que o dizente oferta (27) ou solicita bens (28) ou serviços (29).

(27) Kléber ignora descanso no Cruzeiro e pede para enfrentar o Náutico. (FSP, 15.05.09)

(28) A polícia afirma que os sequestradores pediram $R \$ 2$ milhões de resgate para libertar Michels, em um primeiro contato feito por meio de telefone celular. (FSP, 13.05.09)

(29) França pede ajuda ao Pentágono para localizar Airbus-A330. (FSP, 01.06.09)

O único caso em que pedir configura oferta é o apresentado em 27). Todos os outros são os casos em que há solicitação de bens e serviços, em que se pode fazer uma nova distinção, de modo que o potencial semântico de pedir apresenta uso diferenciado em relação aos outros quatro verbos analisados.

(30) Os governos da Irlanda, Hungria, Romênia e Croácia pediram explicações à Bolívia sobre a morte e detenção dos estrangeiros. (BBC, 22.04.09)

(31) Na última segunda-feira (11), a Procuradoria-Geral do Maranhão pediu que a Polícia Civil investigue suspeitas de superfaturamentos em contratos firmados durante o governo de Lago. (FSP, 15.05.09) 
Note-se que pedir, nesses casos, equivale a solicitar/desejar e a mandar/ exigir/ordenar e não somente falar. É, portanto, verbo de demanda (30) ou de ordem (31), que assim podem ser parafraseados:

(30a) Os governos da Irlanda, Hungria, Romênia e Croácia solicitaram explicações à Bolívia sobre a morte e detenção dos estrangeiros.

(31a) Na última segunda-feira(11), a Procuradoria-Geral do Maranhão mandoulexigiu/ ordenou que a Polícia Civil investigasse suspeitas de superfaturamentos em contratos firmados durante o governo de Lago.

Também se pode argumentar a favor da ocorrência de apenas propostas com o verbo pedir a transposição dessas formas para o modo imperativo, o que resultaria em construções como $30 \mathrm{~b}$ e $31 \mathrm{~b}$, uma com menos e outra com mais força apelativa.

(30b) Os governos da Irlanda, Hungria, Romênia e Croácia pediram à Bolívia: "Deem-nos explicações sobre a morte e detenção dos estrangeiros".

(31b) Na última segunda-feira (11), a Procuradoria-Geral do Maranhão pediu à Polícia Civil: "Investiguem suspeitas de superfaturamentos em contratos firmados durante o governo de Lago.

A escolha do verbo pedir, especialmente em 31, explica-se por questões interpessoais, em que o jornalista opta por demonstrar precaução e também polidez no tratamento da notícia, como é de se esperar na linguagem elaborada dos veículos de grande circulação estudados.

As propostas utilizadas nas orações com pedir são geralmente realizadas por nominalização (como em 32 e 33), item lexical mais denso de significado, uma vez que traz encapsulado em si um processo. É pequeno o número de relatos (como em 33 e 34) e as citações estão ausentes. Com o uso de relatos, fica evidente que os jornalistas optam por não repetir literalmente o que foi dito pelas autoridades, preferindo sempre a retextualização das falas.

(32) Militares americanos disseram que forças afegãs pediram ajuda para reprimir um ataque de insurgentes. (BBC, 07.05.09)

(33) Pouco antes do Pré-Olímpico Mundial, no ano passado, Varejão pediu dispensa da seleção alegando contusão --assim como fizeram Leandrinho e Nenê, outros brasileiros da NBA. (FSP, 24.04.09) 
(34) México pede a diplomatas que informem sobre suspeitas de gripe em seus países. (BBC, 29.04.09)

(35) Nesta terça-feira, o prefeito (governador) de Santa Cruz, o opositor Rubén Costas, pediu que organismos internacionais participem das investigações das mortes. (BBC, 21.04.09)

Passa-se agora à análise dos outros quatro verbos, que se comportam diferentemente de pedir. Embora comumentemente os verbos dizer, afirmar, informar e anunciar sejam complementados tanto com proposições quanto com propostas, o comportamento deles é diverso nas notícias em estudo.

A análise de afirmar e informar demonstra que, nas notícias, são típicos de proposições, em que o dizente oferece informações ao Recebedor.

(36) Estamos monitorando a situação com a ajuda de profissionais de saúde dos sistemas público e privado e estaremos prontos para agir se o perigo existir aqui”, afirmou a ministra da Saúde da África do Sul, Barbara Hogan. (BBC, 01.05.09)

(37) Globo procura sucessor para Galvão Bueno, informa Ooops! (FSP, 16.03.09)

Já os dois restantes (dizer e anunciar) introduzem tanto proposições quanto propostas.

(38) Ao ser informada de que se tratava de uma provável candidata à Presidência, disse: "Nunca ouvi falar dela, mas se for do lado do Lula, voto nela com certeza." (BBC, 29.05.09)

(39) A fabricante de aeronaves Airbus anunciou nesta quarta-feira que vai diminuir o volume de entregas de seu modelo A380, o maior avião comercial do mundo. (FSP, 06.05.09)

\section{Distribuição das mensagens no corpus}

A análise da organização das mensagens onde ocorrem os cinco processos em questão revelou algumas regularidades, que podem ser observadas na Tabela 5. 
Tabela 5: Distribuição da mensagem em relação aos cinco verbos analisados

\begin{tabular}{|l|c|c|c|c|c|c|c|}
\hline & dizer & $\begin{array}{c}\text { afir- } \\
\text { mar }\end{array}$ & $\begin{array}{c}\text { infor- } \\
\text { mar }\end{array}$ & pedir & $\begin{array}{c}\text { anun- } \\
\text { ciar }\end{array}$ & $\begin{array}{c}\text { TO- } \\
\text { TAL }\end{array}$ & T.\% \\
\hline Oração projetada preposta & 762 & 323 & 87 & - & 3 & 1175 & 35,3 \\
\hline $\begin{array}{l}\text { Oração projetada interrompida pela } \\
\text { dominante }\end{array}$ & 2 & 4 & - & - & - & 6 & 0,2 \\
\hline Oração paratática posposta & 8 & 6 & - & - & - & 14 & 0,4 \\
\hline Nominalização & 30 & 3 & 44 & 157 & 97 & 331 & 10.0 \\
\hline $\begin{array}{l}\text { Oração projetada hipotática (sempre } \\
\text { posposta) }\end{array}$ & 804 & 478 & 145 & 66 & 73 & 1496 & 46.0 \\
\hline Oração projetada hipotática sem finito & 133 & 34 & - & 6 & 9 & 182 & 5,5 \\
\hline Outras formas de relato & 7 & 3 & 4 & - & - & 14 & 0,4 \\
\hline Circunstâncias de ângulo & 3 & 5 & 7 & - & 1 & 16 & 0,5 \\
\hline Outros & 47 & 9 & - & - & - & 56 & 1,7 \\
\hline N. TOTAL & 1796 & 865 & 287 & 229 & 183 & 3360 & $100 \%$ \\
\hline \%TOTAL & 53,5 & 25,8 & 8,5 & 6,8 & 5,4 & 100 & 100 \\
\hline
\end{tabular}

A tabela 5 mostra $51,5 \%$ de preferência de hipotaxe; por outro lado, orações paratáticas representam $36 \%$ das orações verbais (projetada preposta + interrompida pela dominante + parataxe posposta), sendo a grande maioria delas preposta à oração projetante, uma importante característica da linguagem jornalística (Sayão 2010).

Os verbos dizer e afirmar são os mais frequentes com esse tipo de ocorrência: das 1195 desse tipo de estrutura, 762 correspondem a orações com dizer, 323 com afirmar, 87 com informar e 3 com anunciar. Esses números de parataxe caracterizam um distanciamento visível do jornalista em relação ao dizer das fontes.

Vale lembrar ainda que, na parataxe, a ordem canônica (oração projetante + oração projetada), em caso de citação, pode ser quebrada com a oração projetada priorizando preceder a projetante, dando origem a tema marcado, realizado pela citação.

(40) "Alguns Estados permitiram que uma ou duas questões dominassem sua abordagem do assunto, permitindo que eles tenham mais valor do que as preocupações de vários grupos de pessoas que sofrem racismo e formas parecidas de intolerância”, teria dito ela, segundo a agência de notícias AFP. (BBC, 20.04.09)

(41) "Esta é uma hora para a comunidade voltar a se unir como ela fez há 10 anos, no dia das mortes", afirmou Kreiling. (BBC, 20.04.09) 
(42) A ex-prefeita e ex-ministra Marta Suplicy receberá um grupo de comunicadoras em sua casa, neste sábado, para almoço em torno da ministra Dilma Rousseff (Casa Civil), informa Renata Lo Prete, editora do "Painel” da Folha. (FSP, 19.05.09)

(43) "O Centro Cultural sudanês será fechado, e as escolas financiadas pelo Sudão serão recuperadas pelo governo chadiano”, anunciou Deby. (FSP, 09.05.09)

Entretanto, há maior interferência do jornalista quando o depoimento da fonte é recontextualizado em relatos (hipotaxe), de vez que, elementos léxico-gramaticais do discurso indireto demandam escolhas que vêm modificar o significado inicial do que foi dito. E, como mostram os dados da tabela 5, apesar de seu alto número, a parataxe ainda é escolha minoritária (1676 hipotaxes além de 371 nominalizações).

(44) Claudia Leitte diz que fingia ser Xuxa quando criança. (FSP, 09.05.09)

(45) A pesquisa afirma que a gripe suína pode matar quatro em cada mil pessoas infectadas. (FSP, 12.05.09)

(46) O site informa que cada pessoa pagou $\mathrm{R} \$ 10$ para entrar no evento ou entregou um quilo de alimento, que foi distribuído a famílias carentes. (FSP, 15.05.09)

(47) Na terça-feira, vários membros do Parlamento anunciaram que devolveriam parte dos gastos reembolsados. (BBC, 13.05.09)

Em 182 casos, referentes aos verbos dizer, afirmar, pedir e anunciar, as orações hipotáticas apresentam formas verbais não finitas, como mostram os exemplos 48 a 51. A preferência se dá pelo infinitivo verbal.

(48) DEM pede afastamento de deputado que diz "se lixar" para opinião pública. (FSP, 11.05.09)

(49) Murcia afirmou ter doado US\$ 2 milhões para a campanha de coleta de assinaturas, requisito necessário para levar a proposta a debate no Congresso. (BBC, 19.05.09)

(50) Sobre o investimento, a Petrobras informou ter gasto $\mathrm{R} \$ 14,4$ bilhões no trimestre, utilizando principalmente a geração própria de caixa da companhia. (FSP, 11.05.09)

(51) O Exército do Sri Lanka anunciou, na manhã deste sábado, ter tomado a última parte da zona costeira do país que era dominada pelos rebeldes do grupo Tigres de Libertação da Pátria Tâmil, no nordeste da ilha. (BBC, 16.05.09) 
Associadas a quatro dos verbos analisados, exceto pedir, ocorrem circunstâncias de ângulo, embora em número muito pequeno. São elas segundo e conforme e caracterizam passagens de discurso mais informal mesclado ao discurso elaborado.

(52) O desaparecimento de aviões de telas de radar durante o voo é "raríssimo", segundo disse à $\mathrm{BBC}$ Brasil o presidente da Federação Internacional das Associações de controladores de Tráfego Aéreo, IFACTA, na sigla em inglês. (BBC, 01.06.09)

(53) Uma nova guerra entre Israel e países árabes ou islâmicos poderá ocorrer em 12 a 18 meses se não houver progressos nas negociações de paz para o Oriente Médio, segundo afirma o rei Abdullah, da Jordânia, em entrevista publicada nesta segundafeira pelo diário britânico The Times. (BBC, 11.05.09)

(54) O STJD (Superior Tribunal de Justiça Desportiva) decidiu nesta sexta-feira suspender o atacante Dentinho, do Corinthians, por três partidas na Copa do Brasil, conforme informou o site "Justiça Desportiva". (FSP, 15.05.09)

(55) A apresentação está marcada para o dia 24 de outubro, segundo anunciou a assessoria do evento nesta quarta-feira (13). (FSP, 13.05.09)

O processo pedir, o mais dialógico dos cinco analisados, pressupõe sempre a presença de um interlocutor a quem é pedida uma ação, nem sempre explícita, mas recuperável no contexto. Por esse motivo, pedir demonstra um comportamento diferenciado em relação aos outros quatro. Não apresenta citações e acompanha um número pequeno de relatos ( $2 \%$ do total de ocorrências). O restante são 157 nominalizações que complementam o processo, o que constitui $47 \%$ das formas de distribuição da mensagem compedir.

(56) O requerimento da oposição pede a investigação de possíveis irregularidades constatadas pela Polícia Federal na empresa.(FSP, 15.05.09)

(57) A Mesa Diretora estabeleceu ainda que os deputados interessados em viajar ao exterior para alguma atividade parlamentar terão que pedir autorização para a Terceira Secretaria e justificar. (FSP, 22.04.09)

A partir das considerações feitas acerca da organização das mensagens em orações com cinco processos analisados, é possível identificarem-se alguns padrões de realização em notícias da Folha de São Paulo e da BBC em português no ano de 2009, o que se apresenta na seguinte seção. 


\section{CONSIDERAÇÕES FINAIS}

Este trabalho teve por objetivo analisar o contexto linguístico em que os cinco processos verbais mais frequentes de um corpus de notícias em português da Folha de São Paulo e a BBC de Londres, on line. Após a análise dos dizentes, foram identificadas as formas verbais, seguindo-se o exame dos os modos de organização das mensagens.

Os dizentes são pessoas dotadas de autoridade para prestar declarações ou fazer depoimentos em notícias de jornais. Os dizentes são apresentados, preferencialmente, antes dos processos, conforme demonstrou a Tabela 4. São eles representados principalmente por nomes próprios ou nomes comuns que identificam o cargo ou a função, de modo a indicar essas fontes como oficiais e conferir autoridade aos depoimentos apresentados. As formas verbais predominantes, por sua vez, são as de terceira pessoa do singular do pretérito perfeito do indicativo, já que a notícia preocupa-se em narrar fatos já acontecidos.

A organização das mensagens, nas notícias analisadas, mostrou algumas regularidades, o que pode ser sistematizado em termos de padrões de realização de acordo com o verbo em uso (Tabela 6).

Tabela 6: Padrões de realização das mensagens com os cinco verbos analisados

\begin{tabular}{|l|l|}
\hline Padrão 1 & dizente + processo (dizer/afirmar/informar) + "que" + proposição ou proposta \\
\hline Padrão 2 & proposição + processo (dizer/afirmar) + dizente \\
\hline Padrão 3 & $\begin{array}{l}\text { dizente }+ \text { processo }(\text { anunciar })+\text { nominalização (proposição ou proposta) } \\
\text { dizente }+ \text { processo }(\text { anunciar })+\text { "que" }+ \text { proposição ou proposta }\end{array}$ \\
\hline Padrão 4 & dizente + processo (pedir) + proposta \\
\hline
\end{tabular}

Para as formas dos verbos dizer, afirmar e informar, os jornalistas demonstram preferência pela organização da mensagem em forma de oração projetante seguida de oração projetada, ou seja, o dizer do outro é informado como um relato iniciado pelo elemento conjuntivo "que". Considera-se este o padrão mais frequente que se realiza nas notícias selecionadas. Ainda para as formas de "dizer" e "afirmar", um segundo padrão pode ser identificado, no qual há a anteposição da citação, seguida do verbo e do dizente. 
O verbo informar foi o que menos variedades de organização apresentou e o verbo pedir foi o mais seguido de nominalizações. Pedir foi um verbo que demonstrou comportamento diferenciado em relação aos demais, uma vez que demonstrou ser complementado somente com propostas. Em notícias, espera-se que os processos verbais, porque constituem um grau superior de semiotização, sejam seguidos de proposições, já que o objetivo da notícia é ofertar informações a seus leitores.

A estrutura hipotática - uso de relatos - é reportar o que é dito por outrem, de modo a passar ao leitor a essência da fala da fonte consultada. Ao contrário, na estrutura paratática - uso de citação - há a apresentação do enunciado da fonte para demonstrar neutralidade.

Já as circunstâncias de ângulo, quando acompanham o processo verbal, ocorrem apenas 16 vezes no corpus e são realizadas com os itens léxicogramaticais segundo e conforme.

Este trabalho investigou o comportamento de cinco processos verbais em notícias sobre política, sociedade, economia, educação e outros, de modo a buscar a compreensão do sistema linguístico do português em um gênero em especial. Como seguimento ao trabalho aqui iniciado, surge a necessidade de também investigar o comportamento de outros processos verbais menos frequentes nas notícias de jornais, as ocorrências de outros participantes da oração verbal, bem como das circunstâncias de ângulo não acompanhadas de processos verbais.

Recebido em setembro de 2011 Aprovado em novembro de 2011 E-mails: sarascotta@yahoo.com.br lbarbara@uol.com.br

\section{REFERÊNCIAS BibLIOGRÁFICAS}

Bakhtin, M. 2000. Estética da criação verbal. 3. ed. São Paulo: Martins Fontes.

Barbara, L.; Macedo, C. M. M. de. 2011. Processos verbais em artigos acadêmicos: padrões de realização da mensagem. In: BARBARA, L. e Moyano, E. Textos em linguagem acadêmica: explorações sistêmico- 
funcionais em espanhol e português. Campinas, SP: Mercado das Letras.

Bernstein, B. 1996. A estruturação do discurso pedagógico: classe, códigos e controle. Petrópolis: Vozes.

Caldas-Coulthard, C. R. 1994. On reporting reporting: the representation of speech in factual and fictional narratives. In: Coulthard, M. Advances in written text analysis. London: Routledge,

Cruz, O. S. e S. da. 2003 Harry Potter and the Chamber of Secrets e sua tradução para o português do Brasil: uma análise dos verbos de elocução, com base na linguística sistêmica e nos estudos de corpora. Universidade Federal de Minas Gerais. Dissertação de Mestrado. Belo Horizonte: UFMG.

FuZER, C. 2008. Linguagem e representação nos autos de um processo penal: como operadores do Direito representam atores sociais em um sistema de gêneros. Universidade Federal de Santa Maria. Tese de doutorado. Santa Maria: UFSM.

Halliday, M. A. K.; Matthiessen, C. M. I. M. 2004. An introduction to functional grammar. 3. ed. London: Hodder Education.

Halliday, M. A. K.; Matthiessen, C. M. I. M. 1999. Construing experience through meaning: a language-based approach to cognition. London: Cassell.

Hunston, S. 1995. A corpus study of some English verbs of attribution. Functions of Language 2, 2: p. 133-158.

Motta-Roth, D.; Marcuzzo, P. 2010. Ciência na mídia: análise crítica de gênero de notícias de popularização científica. Revista Brasileira de Linguística Aplicada, v. 10, n. 3, Belo Horizonte.

Marcuzzo, P. 2011. Ciência em debate? Uma análise das vozes em notícias de popularização científica. Universidade Federal de Santa Maria. Tese de Doutorado. Santa Maria: Universidade Federal de Santa Maria.

SAYÃO, J. 2011. O jornalismo literário e as falas de seus entrevistados: um estudo de linguística sistêmico-funcional. Dissertação (Mestrado em Linguística Aplicada e Estudos da Linguagem). Pontifícia Universidade Católica de São Paulo, São Paulo.

Scotт, M. 2008. Word Smith Tools. Oxford: Oxford University Press.

Thompson, G.; YiYun, Y. 1991. Evaluation in reporting verbs used in academic papers. Applied Linguistics, vol. 12, n. 4, Oxford University Press. 


\section{ANEXO}

Formas verbais mais frequentes no corpus

\begin{tabular}{|l|l|l|l|l|}
\hline Formas & afirmar & informar & pedir & anunciar \\
\hline $\begin{array}{l}\text { Formas mais } \\
\text { frequentes }\end{array}$ & $\begin{array}{l}\text { afirmou } \\
\text { afirma }\end{array}$ & $\begin{array}{l}\text { informou } \\
\text { informa }\end{array}$ & $\begin{array}{l}\text { pediu } \\
\text { pede }\end{array}$ & $\begin{array}{l}\text { anuncia } \\
\text { anunciar } \\
\text { anunciaram }\end{array}$ \\
\hline $\begin{array}{l}\text { Formas menos } \\
\text { frequentes }\end{array}$ & $\begin{array}{l}\text { afirmam } \\
\text { afirmar } \\
\text { afirmaram } \\
\text { afirmando } \\
\text { afirmado } \\
\text { afirmarem }\end{array}$ & $\begin{array}{l}\text { informar } \\
\text { informado } \\
\text { informaram } \\
\text { informada } \\
\text { informados } \\
\text { informará } \\
\text { informem } \\
\text { informarem } \\
\text { informando }\end{array}$ & $\begin{array}{l}\text { pedir } \\
\text { pediram } \\
\text { pedindo } \\
\text { pedimos } \\
\text { pedido } \\
\text { pedem } \\
\text { pedirá } \\
\text { peço } \\
\text { pedia } \\
\text { pedia } \\
\text { pedirei } \\
\text { pediria } \\
\text { peçam } \\
\text { pedirem }\end{array}$ & $\begin{array}{l}\text { anunciam } \\
\text { anunciados } \\
\text { anunciando } \\
\text { anunciadas }\end{array}$ \\
\hline Total de formas & - & 8 & 16 & andas \\
\hline Total de ocorrências & 865 & 287 & 229 & 183 \\
\hline
\end{tabular}

